\title{
Tsunami Warning Systems and the Last Mile
}

\section{Towards Community Based and ICT Enabled Disaster Response Systems}

\author{
Michael Gurstein \\ New Jersey Institute of Technology < gurstein@adm.njit.edu >
}

I guess like everyone else I watched the tragic events of the recent Tsunami unfold on television with a sense of sadness and powerlessness. Not much that one can do from so far away except at this point to make a donation and to make the kinds of noises that get governments to move away from inactivity.

Fortunately my family and I weren't personally impacted so far as we know, but the events took on a very direct force when we saw what seemed to be video from a resort in Thailand where we had stayed 3 years ago and which indicated that the bungalow where we were staying would have been completely inundated by the wave and also the vacation island where my son was exactly one year before had more or less disappeared with a major loss of life.

And thinking of it and scanning the Net for information and for stories I was struck by a couple of things concerning the role (and lack of role) of the Net in these events. The Net appeared to be playing a very significant part in responding to the needs of those at a distance--the on-lookers for information, stories, ways of contributing and so on; families and friends of those possibly impacted with attempts at creating listings of the found and the lost and for those on the ground to manage the concerns and queries of those farther away; and one expects that behind the scenes much of the co-ordination and planning that is being done by aid organizations is being done in ways that are pushing the boundaries of Computer Mediated Communication and managing at a distance.

But I guess I'm a bit surprised that the Net wasn't able (yet?) To bridge the information divides between those who had some idea about what might be coming (the scientists and those immediately impacted) and those who might have been able to make some use of that information in the places where the impact took appreciable time to be realized.

The problem here was not, I think a "the Digital Divide" that is, it wasn't because of a lack of "access" to information, although apparently that too was a problem overall; rather, it seemed to me to be another example of what I've referred to elsewhere as the gap between "access" and "effective use" http://www.firstmonday.dk/issues/issue8 12/gurstein/index.html. From what I can gather many if not most of the communities impacted had Internet "access" in one form or another. What they (and here I would include those with the knowledge who couldn't use it as well as those without knowledge) lacked rather, was the social infrastructure which could have turned Internet access into an "effectively usable" early warning system.

Some had the information - the scientists who detected the earthquake and could understand how that could result in a Tsunami and those who felt the early impact either of the earthquake or the Tsunami-but couldn't use it. Others needed the information - the coastal villages around the Indian Ocean-but couldn't or weren't able to "get it" at least in a timely and usable form. The "degrees of separation" imposed by nationality, language and perhaps most important, domains of knowledge and profession (and the related lack of social linkages, network based trust relationships, communication pathways and so on) impeded the communication between the two groups and one wonders whether this was simply a matter of it still being early days in our Internetted world or something more profound and permanent. 
It seems likely that some sort of Tsunami Early Warning System (TEWS) will be set up in the region probably with an ICT base (I seem to recall something similar being in place for the Pacific Islands, for hurricanes as well as Tsunami's I would assume), but given the infrequency of these events, how useful it will be seems questionable. So I'm wondering now whether, rather than spending a huge amount of money creating a dedicated TEWS, the governments in the region (or better yet the affected communities) wouldn't be better advised to think about how to use the "access" to information that they already have available to them in their communities in ways that will allow them to have some warning in the future. That is how can they develop local means for scanning the information universe to find the information concerning possible local threats and then the create the social means for linking the knowledge that results from this scanning into local structures that can translate that knowledge into effective uses such as early warnings and from there into active (and immediate) disaster response.

Here I'm not thinking just of what are almost singular events like Tsunamis but also of more recurrent weather events and even more common social, economic and political events in the larger world that will have a short term but disastrous (or in some cases positive)impact on community well-being. (dam breaks, rapidly spreading viruses, marauding armies or bandits and so on, on the negative side and opportunities for economic advance, resource exchange, external funds and so on, on the positive side). Let's call this the "Last Mile Warning System" (LMWS).

What then might an effective LMWS look like? That is how do we cover the missing links- the last mile-from the "professional" early warning system that governments can do best with high tech (TEWS), and which seems to be the outcome of the recent Kobe meeting on Disaster Planning, to the "effective use" of the output of those systems by local communities for early warning (LMWS)?.

Just after, the Tsunami events I happened to be in Peru and in the community that is at the base of Macchu Piccu. This community-Aguas Calientes--had an avalanche during the rainy season last year which came down without warning with 10 people killed. I became aware of this when I saw bands of marching school children, banging drums and sounding horns. I followed up on what events were happening and learned that the national government had been slow to react to the event so it seems that the local municipality have taken it upon themselves to set up an early warning observatory (they posted someone permanently in the hills above the village to observe the possible beginnings of an avalanche), a local warning system (he has a horn that he can sound), local safe zones (the village is in a very steep valley so it was necessary to reconnoitre and determine what might be safe and what might not), evacuation techniques (complicated because half the residents at anyone time are transient tourists) and all planned, funded and executed by local community resources. Not very high tech (local knowledge and local direct observation) and not much ICT I think, (I'm not really sure), but this seems to me to be a fantastic example of an LMWS i.e. how emergency preparedness and disaster management could/should be done from the community up, using relatively low cost local resources and local knowledge and something that could be propagated quite widely for example through some applied internet activity, on-line networking etc.etc.

And in the larger and interconnected world of Tsunami's and incipient killer flu's such a low cost approach supplemented by hi tech connectivity could (and in fact did) work wonders. The remarkable story from the Indian newspaper the Hindu ${ }^{1}$ of 01/01/2005 presents how the village Nallavadu, whose entire population of 3,600 was saved by a phone call (and not incidentally by a local knowledge centre (telecentre)) "One of the former volunteers of this (the Swaminathan Teleccentre) programme, Vijayakumar, who now works in Singapore, saw the tsunami warning there. He immediately phoned the village knowledge centre, setting off instant reaction. A warning was repeatedly announced over the public address system and a siren set off. As a result, the tsunami claimed no victims there." This evidently was one of the only coastal villages in all of the Indian Ocean that emerged without a loss of life!

In the context of an "effective use" approach-Vijaykumar, armed with the knowledge (from a TEWS as mediated by the public broadcasting system) had access to a physical infrastructure (the cell and telephone network) to distribute his information but most importantly he had a direct means to link that

${ }^{1}$ http://www.thehindu.com/2005/01/01/stories/2005010107320100.htm 
information in a useful and usable fashion directly into the local community (an LMWS). Also, as a former member of the community and presumably as an acknowledged "knowledge worker" the information that he was passing on had the necessary authority and authenticity to be taken seriously. Also, there was someone at the other end with whom he had a previously established trusted relationship to take the information, and a local social and organizational structure to universally disseminate and translate that information into usable activity (moving to higher ground).

The fact that there was a "community" linkage between the source of the information, Mr. Vijakumar and his counterpart in Nallavadu meant that issues of verification and authenticity of information were immediately overcome. Contrast that to the parallel and sad stories of existing TEWS', the Ocean Scientists in Hawaii who saw the earthquake, knew that a Tsunami was likely and then didn't know who to call (didn't have the social network--LMWS) that would have allowed him to play a similar role to Mr. Vijakumar or the Chief of the Research Bureau in Thailand who also had the information but when he tried to pass it along found that the lines that he was calling were always busy and apparently then gave up.

What is particularly important here and is the significance not simply of the availability of information but also of the capacity to identify what information is important, who the information would be important to, and how to bring that information to the attention of those for whom it will be important and useful. In this, there are clearly roles for enabling instruments such as ICTs at each stage of the process, but what is even more important is the significance of the individual capability to "manage and use" information and the role of (trusted) social/community networks as non-mechanical instruments for distributing the information once received in a form in which it will be immediately responded to.

As something of an aside it might be useful to consider the role of cell phones in this context. In those few instances in the Tsunami disaster where information was transmitted in a sufficiently timely matter and in a form in which it could be used it was invariably transmitted person to person via a cell phone link. The question to ask though, especially given the very widespread distribution of cell phones particularly among the tourist population, is why there was so little direct and beneficial use in this instance either of voice or SMS messaging and what procedures might rectify this for the future particularly since a number of schemes have been proposed which use cell phones as their primary delivery system. In the Nallavadu example, while the transmission was via the cell phone, the key element in saving the community was the local social infrastructure which was available for assimilating, transmitting and using the information in an effective way. The simple act of the transmission via the cell phone would not have been as successful had these not been in place as evidenced by another example where an Australian diving instructor was able to pass a message along to a friend in Thailand who was then able to inform and warn a small number of those immediately in contact with him but where there was no mechanism in place to more widely authenticate and disseminate the information which had been transmitted. Here as elsewhere it is the "social" organization of the Last Mile which will mean whether the information is used or not and whether lives are or are not saved.

The case of the Moken tribe in Thailand who, using traditional knowledge, were also able to survive serves rather to reinforce this position. As a relatively isolated tribe adhering to traditional ways and steeped in traditional knowledge they were able to recognize the signs of the ocean and draw on traditional knowledge for an appropriate response. Having a continuity with traditional knowledge meant that they were able and willing to respond to this without further verification or authentication, something that communities more acculturated to science based knowledge systems might have greater difficulty in doing.

I think the lessons from the above break down into two areas: first the need to figure out ways of translating the outputs of what are likely to be hi tech warnings systems into messages that can be interpreted and used effectively at the local level (the need for a LMD strategy) and secondly the need to support the kind of bottom-up socially-based local emergency/disaster early warning systems and preparedness that would allow local communities to absorb and adapt such information into ways that could be locally useful (the need for a LMD system).

Equally, following the Aguas Calientes case there is the need to find ways for integrating the capacity to "hear" and make sense of locally meaningful knowledge and strategies into local social environments ... I would guess that no government anywhere could find sufficient resources to create and sustain in every 
local community of whatever size the kind of local system that the folks in Aguas Calientes are introducing themselves using their local resources (and local cost structures) and one really can't expect that national governments in most countries except perhaps the very wealthiest are going to have the resources even to sponsor and co-ordinate these... What we need to be looking for are the means to enable and support the creation of a multitude of locally based "social" systems like the one I stumbled across that morning in Aguas Calientes.

But what of Community Informatics (CI)? Is this something to be left to a later stage when other matters have been dealt with and as has been suggested, there are resources and time available for what some regard as "recreational pursuits", or is it the case, as I have a sense, that CI is something more important than that and should be built into the communities directly as they are being re-constructed.

Certainly, the "Community" side of the equation will be of immense importance since much of the reconstruction will of necessity be done by and through existing local communities. However, what of the Informatics side? Some skepticism has been expressed concerning the value of ICTs in this context where the need for water, shelter and food are so pressing. Certainly, there is a need for Management/Organizational Informatics at least from the perspective of managing aid and a considerable degree of infrastructure reconstruction. But I'm thinking also for example, of the need for communities to be able to self-organize and self-manage their reconstruction, to access external resources but to manage the deployment of these locally themselves. I'm also thinking of the probably increased need to create and maintain links with a globally distributed diaspora and well-wishers who can act as sources of support as for example, through remittances. Additionally, I'm thinking of the, as yet largely unrealized, potential for leap-frogging into community based ICT enabled health service, linkages for local economic development, supports to re-building local school systems and so on.

And perhaps most important, what about the creation of the kind of information and knowledge networks that would bind these communities, many of which appear to be extremely isolated and with little "communication" linkage into the larger world as ways of providing early warnings of future such events. In this sense, central to the creation of an effective LDWS is the information/communication linkage into the various globally available TEW systems. Without this linkage being effectively developed and maintained locally, communities will remain as vulnerable tomorrow as they have always been.

In fact, given much of the recent discussion, I'm really concerned that ICT for disaster management will end up resulting in "bigger toys for bigger boys" (a lot of evidence of that in the apparent outcome from the Kobe meeting) - large scale heavy science based sensors, analysers and communicators and not including precisely the kind of socially-based last mile bottom-up component that can actually be (and was) effective at the local level and can be sustainable given local resources (and requirements) once the media blitz has evaporated.

I think it is a given that there will be some form of technology enabled disaster warning systems established as a result of the recent events, what isn't so clear is that those developing and implementing these systems will draw the evident lesson that the Last Mile is a "social mile" and to support or create processes of community development and learning as the most fundamental means for community "security" and that community based ICTs can play a significant enabling role for both of these. 